\title{
Effectiveness of Diffusive Gradient in Thin Films with open and restricted gels in predicting mercury uptake by plants
}

Marta Turulla ${ }^{a}$ Clàudia Fontàs ${ }^{b}$ and Sergi Díez ${ }^{a}$

${ }^{a}$ Environmental Chemistry Department, Institute of Environmental Assessment and Water Research, IDÆA-CSIC, E-08034, Barcelona, Spain

${ }^{b}$ Department of Chemistry, University of Girona, C/Maria Aurèlia Capmany 69,17003 Girona, Spain

\begin{abstract}
Worldwide concern regarding mercury $(\mathrm{Hg})$ toxicity and the associated risk for human beings calls for an easy tool to determine the bioavailable $\mathrm{Hg}$ which would be able to predict the transfer of $\mathrm{Hg}$ from soils to crops. In this study, Diffusive Gradient in Thin Films (DGT) is used as a passive sampler tool to determine the bioavailability of $\mathrm{Hg}$ in agricultural soils containing different amounts of $\mathrm{Hg}\left(0.016\right.$ and $\left.0.65 \mathrm{mg} \mathrm{kg}^{-1}\right)$. For the first time, we have used homemade manufactured open and restricted diffusive layers to distinguish between inorganic and organic bioavailable $\mathrm{Hg}$ species in soil. It should be highlighted that this is the first study that demonstrates the successful use of restricted gel for the determination of inorganic $\mathrm{Hg}$ species in soil. Moreover, a model program has been used to calculate the effective concentration for predicting $\mathrm{Hg}$ concentration uptake by plants. For this purpose, lettuces were planted in the different soils tested to determine $\mathrm{Hg}$ soil-to-plant transfer. Concentrations of $\mathrm{Hg}$ obtained by DGT measurements in the soil matched the $\mathrm{Hg}$ concentration found in lettuce roots, confirming the effectiveness of this technique in predicting $\mathrm{Hg}$ uptake by plants.
\end{abstract}

Keywords: Hg; soil; lettuce; DGT; open diffusive gel; restricted diffusive gel 


\section{Introduction}

Metal content in soils is increasing due to both natural processes and anthropogenic activities (Kabata-Pendias 2011). In the case of agricultural soils, the presence of metals is an issue of increasing concern because metal soluble forms can be transferred from soil to plants and may pose a health risk (Rodrigues et al, 2012). Different methods have been developed to assess the bioavailability of metals in soils. Chemical methods are widely used and are based on chemical extraction and further correlation of the labile metals determined by single or sequential extraction approaches (Kim and Hyun 2015). The Diffusive Gradient in Thin Film (DGT) has emerged as a good alternative for measuring metal bioavailability (Davison and Zhang 1994). Since then, a great number of studies have demonstrated that the DGT technique is a versatile in situ passive sampling tool for the measurement of metals and oxyanions, and also a potential tool for the determination of inorganic nutrients and organics ( $\mathrm{Li}$ et al, 2016). The DGT technique is based on the diffusion of the dissolved species through a membrane diffusion layer and their accumulation in a resin enclosed in a hydrogel (Fernández-Gómez et al. 2014). It is well proven that this technique is highly selective for different trace elements depending on the selective resin used in the hydrogel. In the case of $\mathrm{Hg}$, the specific resin includes thiol groups, such as Spheron-thiol (Turull et al. 2017) or 3-mercaptopropyl functionalized silica gel (Fernández-Gómez et al. 2014). According to Fick's first law, the concentration of the metal in the solution $(C)$ is:

$$
\mathrm{C}=\frac{\mathrm{M} \Delta \mathrm{g}}{\mathrm{DAt}}
$$

where $\mathrm{D}$ is the diffusion coefficient of the $\mathrm{Hg}$ in the diffusive layer, $\mathrm{M}$ is the mass of $\mathrm{Hg}$ accumulated by the resin, $\Delta \mathrm{g}$ is the thickness of the diffusive layer, $\mathrm{A}$ is the exposure surface area and $\mathrm{t}$ is the deployment time. Moreover, the diffusion coefficient (D) of $\mathrm{Hg}$ in the diffusive gel can be calculated from the slope $(s)$ of the relationship between the amount of $\mathrm{Hg}$ accumulated by the DGT units (normalised for the concentration of $\mathrm{Hg}$ in solution) and the deployment time according to:

$$
\mathrm{D}=\frac{s \Delta \mathrm{g}}{\mathrm{A}}
$$

The DGT technique can also be used to perform speciation studies of trace elements in which a hydrogel with a different pore size is used as the diffusive layer (Shiva et al. 2015). Generally, DGT studies use open diffusive layer, a type of polyacrylamide hydrogel with a 
large pore higher than $5 \mathrm{~nm}$, which allows almost free diffusion of both inorganic and organic species. In comparison, very few studies employ restricted diffusive layers that uses polyacrylamide gel with a bis-acrylamide cross-linker with a pore size smaller than $1 \mathrm{~nm}$, which restricts the transport to inorganic species (Shiva et al. 2015). The number of studies using open and restricted diffusive layer for predicting trace metal bioavailability are scarce. Moreover, only a few studies exist on $\mathrm{Hg}$ soil-to-plant bioavailability (Cattani et al. 2008; Liu et al. 2012), while absolutely no studies have been conducted using restricted layer for this metal.

Our main objective was to evaluate the two types of diffusive gels with different pore size to determine the ratio of inorganic and organic $\mathrm{Hg}$ species in two agricultural soils. Moreover, the effectiveness of this technique was investigated by analyzing $\mathrm{Hg}$ uptake from lettuces growing in these soils.

\section{Experimental design}

\subsection{Soil characteristics}

An agricultural soil in the peri-urban area of Barcelona (Spain), and an ecological agricultural field used as a control were used in this study. Ten subsamples of topsoil (0$20 \mathrm{~cm}$ ) were collected in a grid $(10 \mathrm{~m} \times 10 \mathrm{~m})$ using a stainless steel trowel and combined into a single sample $(\mathrm{N}=5)$. Soil $\mathrm{pH}$ and conductivity were determined with deionized water at a 1:2 solid:liquid ratio using a pH meter Crison GLP22 and a Hach CDC401, respectively. The organic matter was analyzed as the percentage loss on ignition using a $2.0 \mathrm{~g}$ soil in an oven (Carbolite CWF 1300 ) at $550^{\circ} \mathrm{C}$ for $1 \mathrm{~h}$ (Walter E. Dean 1974). $\mathrm{Hg}$ in all samples was determined using an AMA-254 instrument (Altec, Czech Republic) (Díez et al., 2007). The accuracy was checked with the certified material DORM-3 with values lower than $5 \%$.

\subsection{Pot experiments}

Lettuces (Lactuca sativa L. cv. Batavia) were planted in $2.5 \mathrm{~L}$ cylindrical pots filled with 2 $\mathrm{kg}$ air-dried soil for every set. One lettuce was planted per pot (5 replicates per set). Plants were irrigated manually every day $(50-75 \mathrm{~mL}$ per pot) with Tarssan nutritive solution. After 48 days of growth, leaves and roots were harvested separately and washed off with deionized water. The samples were dried in an oven at $60^{\circ} \mathrm{C}$. A mixture of soil from each set of pots was made and passed through a $0.5-\mathrm{mm}$ sieve prior to analysis. 


\subsection{Diffusive Gradient in thin film (DGT)}

\subsubsection{Hydrogels and binding layers preparation}

The open diffusive layers were prepared with acrylamide patented agarose-derived crosslinker (Fernández-Gómez et al. 2014). The restricted diffusive layers were prepared according to Shiva et al. (2015) with some minor modifications. Briefly, a gel solution was prepared by mixing $40 \%$ acrylamide/bis-acrylamide solution in a $1: 1.66$ ratio with Milli-Q water and was preserved in the fridge for at least one day. $6.67 \mu \mathrm{L}$ of tetramethylethylenediamine and $23 \mu \mathrm{L}$ of $10 \%(\mathrm{~m} / \mathrm{v})$ ammonium persulphate in Milli-Q water were added for every $3.33 \mathrm{~mL}$ of gel solution and then stirred vigorously. After combining these three solutions, the mixed solution was pipetted into two plates of glass separated by a $0.5 \mathrm{~cm}$ thick Teflon spacer and allowed to polymerize at room temperature for $45 \mathrm{~min}$. After that, the polymerized gel was rinsed with Milli-Q water for at least $24 \mathrm{~h}$ changing the water 2-3 times.

For the binding layers, $0.33 \mathrm{~g}$ of 3-mercaptopropyl functionalized silica gel was used per glass, mixing with the same gel solution as for the hydrogel gels. Finally, the same casting procedure was used as for the other gels, but using a $0.25 \mathrm{~cm}$ Teflon spacer. The characteristics of DGT gels are summarized in Table 1.

Table 1. Composition and characteristics of open and restricted diffusive layers

\begin{tabular}{lccc}
\hline \multicolumn{1}{c}{ Parameters } & Units & Open gel & Restricted gel \\
\hline Resin thickness & $\mathrm{mm}$ & 0.4 & 0.25 \\
Diffusive gel thickness & $\mathrm{mm}$ & 0.8 & 0.5 \\
Gel surface area & $\mathrm{cm}^{2}$ & 3.14 & 3.14 \\
Gel solution & & polyacrylamide cross-linked & polyacrylamide cross-linked \\
Reagent:water ratio & & with agarose & with bis-acrylamide \\
Setting temperature & & $1: 3.1$ & $1: 1.66$ \\
Pore size & ${ }^{\circ} \mathrm{C}$ & $42-45$ & $22-25$ \\
Hg content: Blank (resin gel) & $\mathrm{ng} \mathrm{Hg}$ & higher than 5 & smaller than 1 \\
\hline
\end{tabular}


A plastic mold piston design with a $2 \mathrm{~cm}$ diameter window was used to assembly the gels as described elsewhere (Fernández-Gómez et al. 2014).

\subsubsection{Determination of $\mathrm{Hg}$ in soils}

Soil preparation consisted of adding a $40 \mathrm{~g}$ sample in a Petri dish and maintaining it at $100 \%$ maximum water holding capacity with Milli-Q water at $25^{\circ} \mathrm{C}$ for $48 \mathrm{~h}$ to ensure the equilibrium between fractions and soil (Yao et al. 2016). Triplicates for every sample set were done. Three DGT devices per soil were pressed onto the surface of the soil slurries and kept for $24 \mathrm{~h}$ at $25^{\circ} \mathrm{C}$ and covered by a Petri dish to avoid potential contamination and ensure that moisture was stable. After retrieval, deionized water was used to carefully wash the filter membrane to remove soil particles from the surface. For pore water analysis, the soil slurry was centrifuged at $3000 \mathrm{rpm}$ for $20 \mathrm{~min}$ followed by filtration $(0.45$ $\mu \mathrm{m})$. Prior to analysis, each soil solution was acidified with $1 \mathrm{M} \mathrm{HNO}_{3}$ and stored at $4^{\circ} \mathrm{C}$.

To interpret DGT measurements, the Hg concentration from DGT can be converted to an effective concentration $\left(C_{E}\right)$ using:

$$
\mathrm{C}_{\mathrm{E}}=\frac{\mathrm{C}_{\mathrm{DGT}}}{\mathrm{R}_{\text {diff }}}
$$

$R_{\text {diff }}$ is the ratio of the concentration at the DGT interface to the concentration in the bulk soil solution, and it is obtained when metals reach the binding resin only through simple diffusion. It is calculated by the numerical model DIFS (DGT-induced fluxes in sediments) (Sochaczewski et al. 2007). Input parameters were used to calculate $R_{\text {diff, }}$ soil porosity and particulate concentration (Zhang et al. 2004). $C_{E}$ is the metal concentration effectively available from the soil solution and the solid phase, so, theoretically, it is the same concentration as that is found in the rhizosphere of plants. Statistical analysis was evaluated by IBM SPSS statistics 25 (SPSS Inc., Chicago, USA). Values are expressed as mean \pm standard deviation. The one-way analysis of variance was used to evaluate $\mathrm{Hg}$ in different lines and parts of the plants. A difference of $p$ lower than 0.05 was considered statistically significant. 


\section{Results and discussion}

\subsection{Soil properties}

$\mathrm{Hg}$ concentration in each soil sample was found to be $0.016 \mathrm{mg} \mathrm{kg}^{-1}$ for Control soil and $0.641 \mathrm{mg} \mathrm{kg}^{-1}$ for Agricultural soil, below the European regulation threshold value (i.e. 1$\left.1.5 \mathrm{mg} \mathrm{kg}^{-1}\right)$ (EU 1986) in both cases.

Physicochemical characteristics such as texture, $\mathrm{pH}$, conductivity and organic matter were sandy loam, 7.15, $1.13 \mathrm{mS}$ and $2.72 \%$ for Control soil, whereas for Agricultural soil they were clay loam, $7.29,1.73 \mathrm{mS}$ and $6.52 \%$, respectively. The $\mathrm{pH}$ and conductivity values between the studied soils were comparable, while organic matter and texture were the main parameters that could explain the different mobility of $\mathrm{Hg}$. The texture of the agricultural soil had a higher sorption capacity in comparison with the control soil because of the higher clay content in soil and, depending on the organic acids, organic matter could reduce or increase $\mathrm{Hg}$ bioavailability by forming insoluble or soluble complexes (Hasegawa et al., 2016). In this sense, adsorbents such as clay minerals and modified clays are effective for the removal of metal ions from wastewater (Gu et al., 2018), and from soils (Kurczewska et al., 2015).

\subsection{Studies on Hg bioavailability in soils}

A time-series experiment was performed separately for both types of DGT with the aim of obtaining the diffusion coefficient of $\mathrm{Hg}$ in the diffusive layers. Two experiments were carried out using a glass tank $(3 \mathrm{~L})$ containing $\mathrm{NaCl}(0.1 \mathrm{M})$ solution and $\mathrm{pH} 7$ and spiked with $4 \mathrm{ng} \mathrm{mL}{ }^{-1}$ of $\mathrm{Hg}$ at $20^{\circ} \mathrm{C}$. Two DGTs were retrieved at different times to obtain the calibration curve. The value of mass $(M)$ was used to calculate the diffusion coefficient with equation 1 for every time-series deployment.

Excellent linearity for both open and restricted gels was observed (Figure 1) over a $50 \mathrm{~h}$ time-series experiment, indicating the suitability of both binding layers to measure $\mathrm{Hg}$. According to equation 2, the slope of the line was used to calculate the diffusion coefficient for both DGT types. This value was $1.79 \times 10^{-6} \mathrm{~cm}^{2} \mathrm{~s}^{-1}$ for restricted gel, whereas for open gel it was $3.08 \times 10^{-6} \mathrm{~cm}^{2} \mathrm{~s}^{-1}$. The fact that both diffusion coefficient values were of the same order of magnitude, but the value for the restricted gel slightly lower, was also described by Shiva et al. (2015) for different metals from $\mathrm{Hg}$ 


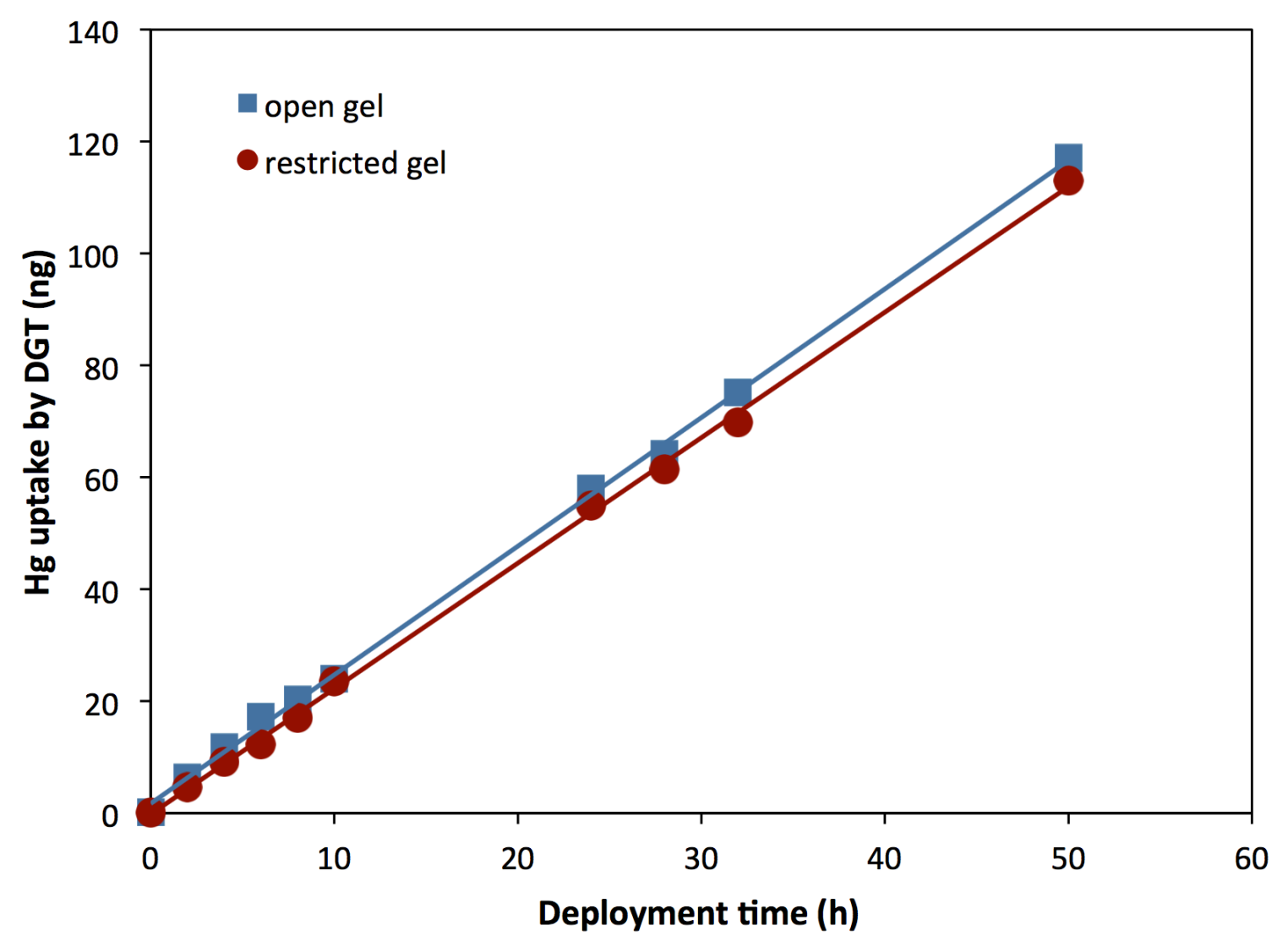

Figure 1. Time-series of $\mathrm{Hg}$ accumulation using DGT with open and restricted diffusive layer. There is a high linear relationship between the mass of mercury accumulated in the resin normalized by the $\mathrm{Hg}$ concentration in the solution in the period of time investigated. Linear equation for open gel: $y=2.30 x+1.73, r^{2}=0.999$; and for restricted gel: $y=2.24 x+0.18, r^{2}=0.999$. The diffusion coefficient (D) of $\mathrm{Hg}$ in the diffusive layer can be calculated from the slope of the relationship between the amount of $\mathrm{Hg}$ accumulated by the DGT and the deployment time according to equation 2 . The two types of DGT performed equally well, as evidenced by the regression coefficients of the two linear curves $\left(r^{2}\right.$ higher than 0.99). Note that the two curves have similar slopes, although the open gel showed the fastest rate of uptake (the greatest slope) and, therefore, a higher diffusion coefficient.

\subsection{DGT and lettuce measurements}

Applying diffusion coefficient values for restricted and open gels, $\mathrm{Hg}$ concentration for both DGT were obtained (Table 2). 
Table 2. Comparison of $\mathrm{Hg}$ concentration in soil using open $\left(\mathrm{C}_{\mathrm{DGT}}-\mathrm{ODL}\right)$ and restricted $\left(\mathrm{C}_{\mathrm{DGT}}-\mathrm{RDL}\right)$ gels, the ratio of the concentration at the DGT interface to the concentration in the bulk soil solution $\left(R_{\text {diff }}\right)$, the calculated effective concentration $\left(C_{E}\right)$ and low molecular species (LMS) for Control soil and Agricultural soil.

\begin{tabular}{|c|c|c|c|c|c|}
\hline Line & $\mathbf{C}_{\mathrm{DGT}}-\mathrm{ODL}\left(\mathrm{ng} \mathrm{mL}^{-1}\right)$ & $\left.\mathbf{C}_{\mathrm{DGT}}-\mathrm{RDL}_{(\mathbf{n g ~ m L}}{ }^{-1}\right)$ & $\mathbf{R}_{\text {diff }}$ & $\mathbf{C}_{\mathrm{E}}\left(\mathbf{n g ~ g}^{-1}\right)$ & $\mathbf{L M S}(\%)$ \\
\hline Control soil & $0.186 \pm 0.040$ & $0.130 \pm 0.018$ & 0.053 & 3.514 & 70 \\
\hline Agricultural soil & $1.616 \pm 0.170$ & $1.567 \pm 0.881$ & 0.118 & 13.696 & 97 \\
\hline
\end{tabular}

$\mathrm{LMS}(\%)=\left(\mathrm{C}_{\mathrm{DGT}}-\mathrm{RDL} / \mathrm{C}_{\mathrm{DGT}}-\mathrm{ODL}\right) \times 100$ (indicative of inorganic $\mathrm{Hg}$ species in the soil)

As described above, $R_{\text {diff }}$ is calculated by the DGT-induced fluxes in sediments model. Because the obtained $R_{\text {diff }}$ is between 0 and 1 , this value shows that only a small fraction of the $\mathrm{Hg}$ concentration could be determined by the DGT. $\mathrm{C}_{\mathrm{E}}$ could be estimated by the ratio between the calculated concentration of $C_{D G T}-O D L$ and $R_{\text {diff. }}$ This $C_{E}$ is the value to be compared with the $\mathrm{Hg}$ uptake by roots.

$\mathrm{Hg}$ concentrations found in both lettuce leaves and roots are summarized in Figure $2 . \mathrm{Hg}$ values in leaves were not significantly different between Control soil and Agricultural soil, despite the great difference in $\mathrm{Hg}$ concentration in the soils. This fact can be explained by the role of plants as either a source or a sink for atmospheric $\mathrm{Hg}$ through a vegetation-air mechanism, as described in Ericksen and Gustin 2004. However, in the case of roots, the uptake is only due to the presence of metal in the soil. $\mathrm{Hg}$ in lettuce roots grown in Control was $2.88 \pm 0.28 \mathrm{ng} \mathrm{g}^{-1}$, but this value dramatically increased in the case of roots from Agricultural soil, reaching a value of $14.08 \pm 1.62 \mathrm{ng} \mathrm{g}^{-1}$. It is worth mentioning that the difference between root concentration and calculated $C_{E}$ was only $18 \%$ for control and $2 \%$ for Agricultural soil. This good agreement demonstrates that the DGT technique can predict $\mathrm{Hg}$ content in plants due to its ability to mimic the process of uptake limited by diffusion, accounting for processes that traditional soil extractions are not able to determine (i.e. slow desorption) (Muhammad et al. 2012). Metal in the pore water or in soil cannot indicate the $\mathrm{Hg}$ available for plants because the resupply to the pore water from the solid, owing to depletion, is not taken into account (Wang et al. 2018). 


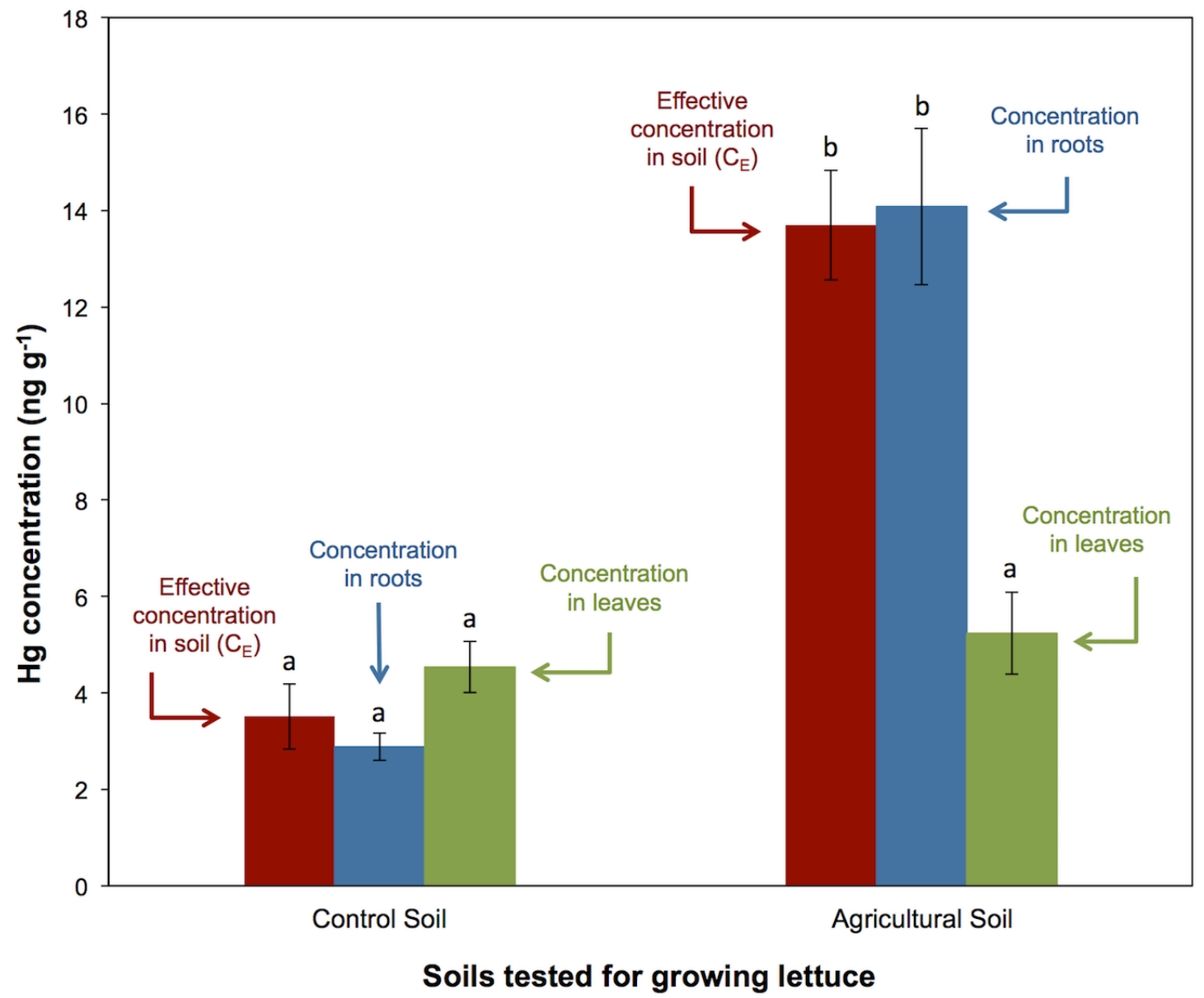

Figure 2. Effect of the different soils used to grow lettuces on $\mathrm{Hg}$ content found in lettuce roots, and leaves and effective concentration $\left(\mathrm{C}_{\mathrm{E}}\right)$ in soil. Measurements of $\mathrm{Hg}$ in roots and leaves were performed by direct analysis of tissues, whereas $C_{E}$ was measured by DGT in soil according to equation 3. Error bars are the standard deviations of quintuplicates. Different letters within the graph indicate significant differences. Note that $\mathrm{Hg}$ concentration measured in the soil by DGT has no significant differences with $\mathrm{Hg}$ in roots in both types of soil, and only with leaves in the control. This indicates that $\mathrm{Hg}$ concentration in soil by DGT is related to $\mathrm{Hg}$ in roots.

The percentage of low molecular Hg species, which is the fraction preferentially available by plants, is also shown in Table 2 . A higher percentage $(\sim 10 \%)$ was found in Agricultural soil versus Control soil, although in both cases the predominant fraction is mainly inorganic. Higher mobility of Agricultural soil can be confirmed by the coefficient $R_{\text {diff }}$ since higher values were obtained (0.118 vs. 0.053) (Kovaříková et al. 2007). Our values matched with the fraction of different metals studied in two different soils (Dočekalová et al. 2012). It is known that the $\mathrm{Hg}$ concentration in most crops is mainly in its inorganic form (WHO 1991) which is more mobile than the organic species because of the adsorption into 
soil particles, reducing the direct flow into the soil water (Yu et al. 2018). Therefore, the use of both DGT devices allows us to know which part can be rapidly uptaken by plants in the early growth stages.

\section{Conclusion}

This is the first study that successfully determines inorganic $\mathrm{Hg}$ species in soils using restricted diffusive layer DGT devices with a small pore size. The study results have indicated that DGT is very useful for predicting $\mathrm{Hg}$ uptake by lettuce roots. Moreover, combining DGT with open and restricted gels has proven to be a successful, fast and simple test for assessing bioavailable and low molecular $\mathrm{Hg}$ species, respectively. Hence, a great potential for determining the uptake of other toxic trace metals to vegetables can be expected. Future studies on $\mathrm{Hg}$ mobility and bioavailability and possibly on trace metals from different soil amendments (i.e. manure, peat, compost, or biochar), and their further incorporation in vegetable crops, are anticipated.

\section{Acknowledgments}

The authors gratefully acknowledge the financial support of the Spanish Ministry of Economy, Industry, and Competitiveness (MEIC) through projects AGL2014-59353-R and CTM2016-78798-C2-2-P (AEI/FEDER/UE).

\section{References}

Cattani I, Spalla S, Beone GM, et al (2008) Characterization of mercury species in soils by HPLC-ICP-MS and measurement of fraction removed by diffusive gradient in thin films. Talanta 74:1520-1526. doi: 10.1016/j.talanta.2007.09.029

Davison W, Zhang H (1994) In-situ speciation measurements of trace components in natural waters using thin-film gels. Nature 237:546-548. doi: 10.1038/367546a0

Díez S, Montuori P, Querol X, Bayona JM (2007) Total mercury in the hair of children by combustion atomic absorption spectrometry (Comb-AAS). J Anal Toxicol 31:144-149. doi: 10.1093/jat/31.3.144

Dočekalová H, Kovařková V, Dočekal B (2012) Mobility and bioaccessibility of trace metals in soils assessed by conventional extraction procedures and passive diffusive samplers. Chem Speciat Bioavailab 24:261-265. doi:

10.3184/095422912X13490131100968

Ericksen JA, Gustin MS (2004) Foliar exchange of mercury as a function of soil and air mercury concentrations. Sci Total Environ 324:271-279. doi:

10.1016/j.scitotenv.2003.10.034 
EU (1986) Council Directive of 12 June 1986 on the protection of the environment, and in particular of the soil, when sewage sludge is used in agriculture (86/278/EEC). Off $\mathrm{J}$ Eur Communities 181:6-12. https://eur-lex.europa.eu/legalcontent/EN/TXT/?uri=celex\%3A31986L0278 Accessed 16 Jan 2019.

Fernández-Gómez C, Bayona JM, Díez S (2014) Comparison of different types of diffusive gradient in thin film samplers for measurement of dissolved methylmercury in freshwaters. Talanta 129:486-490. doi: 10.1016/j.talanta.2014.06.025

Gu S, Kang X, Wang L, Lichtfouse E, Wang C. (2018) Clay mineral adsorbents for heavy metal removal from wastewater: a review. Environ Chem Lett. doi: 10.1007/s10311018-0813-9

Hasegawa H, M M Rahman I, A Rahman M 2016 The effects of soil properties to the extent of soil contamination with metals. In: Alamgir Md(ed) Environmental remediation technologies for metal-contaminated soils. Springer, Tokio, Japan, pp 119

Kabata-Pendias A (2011) Trace elements in soils and plants, 4th ed. Boca Raton, London, New York

Kim J, Hyun S (2015) Nonequilibrium leaching behavior of metallic elements (Cu, Zn, As, $\mathrm{Cd}$, and $\mathrm{Pb}$ ) from soils collected from long-term abandoned mine sites. Chemosphere 134:150-158. doi: 10.1016/j.chemosphere.2015.04.018

Kovaříková V, Dočekalová $H$, Dočekal $B$, Podborská M (2007) Use of the diffusive gradients in thin films technique (DGT) with various diffusive gels for characterization of sewage sludge-contaminated soils. Anal Bioanal Chem 389:2303-2311. doi: $10.1007 / \mathrm{s} 00216-007-1628-x$

Kurczewska J, Grzesiak P, Łukaszyk J, Gabała E, Schroeder G (2015) Environ Chem Lett 13: 319. doi:10.1007/s10311-015-0504-8

Li C, Ding S, Yang L, Wang Y, Ren M, Chen M, Fan X, Lichtfouse E (2018) Diffusive gradients in thin films: devices, materials and applications. Environ Chem Lett. doi:10.1007/s10311-018-00839-9

Liu J, Feng X, Qiu G, et al (2012) Prediction of Methyl Mercury Uptake by Rice Plants (Oryza sativa L.) using the Diffusive Gradient in Thin Films Technique. Environ Sci Technol 46:11013-11020. doi: 10.1021/es302187t

Muhammad I, Puschenreiter M, Wenzel WW (2012) Cadmium and Zn availability as affected by $\mathrm{pH}$ manipulation and its assessment by soil extraction, DGT and indicator plants. Sci Total Environ 416:490-500. doi: 10.1016/j.scitotenv.2011.11.029

Rodrigues SM, Henriques B, Reis AT, Duarte AC, Pereira E, Römkens PFAM (2012) Environ Chem Lett 10: 61. doi: 10.1007/s10311-011-0329-z

Shiva AH, Teasdale PR, Bennett WW, Welsh DT (2015) A systematic determination of diffusion coefficients of trace elements in open and restricted diffusive layers used by the diffusive gradients in a thin film technique. Anal Chim Acta 888:146-154. doi: 10.1016/j.aca.2015.07.027

Sochaczewski $Ł$, Tych W, Davison B, Zhang H (2007) 2D DGT induced fluxes in sediments and soils (2D DIFS). Environ Model Softw 22:14-23. doi: 10.1016/j.envsoft.2005.09.008

Turull M, Komarova T, Noller B, et al (2017) Evaluation of mercury in a freshwater 
environment impacted by an organomercury fungicide using diffusive gradient in thin films. Sci Total Environ. doi: 10.1016/j.scitotenv.2017.10.081

Walter E. Dean J (1974) Determination of Carbonate and Organic Matter in Calcareous Sediments and Sedimentary Rocks by Loss on Ignition: Comparison With Other Methods. SEPM J Sediment Res 44:242-248. doi: 10.1306/74D729D2-2B21-11D78648000102C1865D

Wang S, Wu Z, Luo J (2018) Transfer Mechanism, Uptake Kinetic Process, and Bioavailability of $\mathrm{P}, \mathrm{Cu}, \mathrm{Cd}, \mathrm{Pb}$, and $\mathrm{Zn}$ in Macrophyte Rhizosphere Using Diffusive Gradients in Thin Films. Environ Sci Technol 52:1096-1108. doi: 10.1021/acs.est.7b01578

WHO (1991) Inorganic mercury. Environ Heal Criteria 168. http://www.inchem.org/documents/ehc/ehc/ehc118.htm Accessed 16 Jan 2019

Yao Y, Sun Q, Wang C, et al (2016) The combination of DGT technique and traditional chemical methods for evaluation of cadmium bioavailability in contaminated soils with organic amendment. Int J Environ Res Public Health 13:1-14. doi: 10.3390/ijerph13060595

Yu H, Li J, Luan Y (2018) Meta-analysis of soil mercury accumulation by vegetables. Sci Rep 8:1-10. doi: 10.1038/s41598-018-19519-3

Zhang H, Lombi E, Smolders E, McGrath S (2004) Kinetics of Zn release in soils and prediction of $\mathrm{Zn}$ concentration in plants using diffusive gradients in thin films. Environ Sci Technol 38:3608-3613. doi: 10.1021/es0352597 